\title{
Paclitaxel Preparation
}

National Cancer Institute

\section{Source}

National Cancer Institute. Paclitaxel Preparation. NCI Thesaurus. Code C61078.

Any formulation containing paclitaxel, an antimitotic taxane. 